\title{
Message content features and social media engagement: evidence from the media industry
}

\author{
Gillian Moran \\ School of Business, Maynooth University, Maynooth, Ireland \\ Laurent Muzellec \\ Trinity Centre for Digital Business, University of Dublin, Dublin, Ireland, and \\ Devon fohnson \\ Feliciano School of Business, Montclair State University, Montclair, New Jersey, USA
}

\begin{abstract}
Purpose - This paper aims to uncover the drivers of consumer-brand engagement on Facebook, understood here as users' behavioral responses in the form of clicks, likes, shares and comments. We highlight which content components, interactivity cues (calls to action [CTA]) and media richness (e.g. video, photo and text) are most effective at inducing consumers to exhibit clicking, liking, commenting and sharing behaviors toward branded content.

Design/methodology/approach - This study analyzes 757 Facebook-based brand posts from a media and entertainment brand over a 15-week period. It investigates the relationship between interactive cues and media richness with consumer engagement using a negative binomial model.

Findings - Results show positive relationships for both interactivity cues and media richness content components on increasing consumer-brand engagement outcomes. The findings add clarity to previous inconsistent findings in the marketing literature. CTAs enhance all four engagement behaviors. Media richness also strongly influences all engagement behaviors, with visual imagery (photos and videos) attracting the most consumer responses.

Research limitations/implications - The sampled posts pertain to one brand (a radio station) and are thus concentrated within the media/ entertainment industry, which limits the generalizability of findings. In addition, the authors limit their focus to Facebook but recognize that findings may differ across more visual or textual social networking sites.

Practical implications - The authors uncover the most effective pairings of media richness and interactivity components to trigger marketerdesired, behavioral responses. For sharing, for example, the authors show that photo-based posts are more effective on average than video-based posts. The authors also show that including an interactive call to act to encourage one type of engagement behavior has a near-universal effect in increasing all engagement behaviors.

Originality/value - This study takes two widely used concepts within the communications and advertising literatures - interactivity cues and media richness - and tests their relationship with engagement using real and actual users' data available via Facebook Insights. This method is more robust than surveys or wall scrapping, as it mitigates Facebook's algorithm effect. The results produce more consistent relationships than previous content marketing studies to date.
\end{abstract}

Keywords Facebook, Brand engagement, Brand communication, Social media, User-generated content, Content marketing, Media richness, Call-to-action, Engagement

Paper type Research paper

\section{Introduction}

Brands are actively using social media to get their messages out to consumers. Social media offered the promise of direct access to an engaged consumer-base, eager to listen and converse with brands (Mangold and Faulds, 2009), yet that promise remains largely unrealized. Instead, brand communications vie and compete for consumer attention against friend posts, celebrity updates, sports results and news headlines. Social media sites such as Facebook do offer brands unprecedented access to a

The current issue and full text archive of this journal is available on Emerald Insight at: https://www.emerald.com/insight/1061-0421.htm

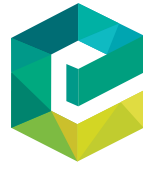

Journal of Product \& Brand Management

29/5 (2020) 533-545

(C) Emerald Publishing Limited [ISSN 1061-0421]

[DOI 10.1108/JPBM-09-2018-2014] vast number of active community members, but brands still find it challenging to engage these users (Colliander et al., 2015). Consumer engagement, understood here as a behavioral response manifested in actions such as clicks, likes, comments and shares (van Doorn et al., 2010), is a key social media marketing goal today. However, it is proving difficult to accomplish as engagement rates with branded content are reportedly falling despite an increase in content marketing efforts by brands (Erskine, 2018).

A key enduring question for marketers and community managers then concerns how to drive engagement with online consumers or "fans" (eMarketer, 2015). For instance, can

Received 13 September 2018

Revised 15 February 2019

9 May 2019

3 September 2019

Accepted 7 September 2019 
marketer-controlled elements of content marketing be leveraged to enhance consumer engagement on social media sites? In particular, marketers seek guidance on which calls-toaction (CTAs) drive consumer engagement and whether videos, pictures or simple plain text are most effective in enticing potential consumers to engage through actions such as liking, sharing and commenting.

Unfortunately, academic literature has so far provided incomplete answers to this acute managerial question. Some insights have emerged with regard to the relationships between content types (organic vs paid and experience-centric vs promotional content) and consumer responses (Kim and Song, 2018; Vargo, 2016). In addition studies are beginning to consider how content marketing, in terms of message length, tone of voice and appeal, is impacting on customer engagement (Lee et al., 2014; Stephen et al., 2015). Nevertheless there is still very little guidance on the relationship between message format, interactive stimulus and consumer engagement. De Vries et al. (2012) initiated this conversation and posited some relationships between media richness (vividness), interactivity and brand post popularity and it is to this line of content marketing research that we wish to contribute.

Content marketing studies to date, although insightful, have failed to provide definitive answers because of inconsistent findings emerging. These inconsistencies may be borne out of methodological limitations, which potentially constrain the data. Notably, these studies have largely measured consumerbrand engagement via self-report surveys or data scraping methods. Albeit widely accepted, these methods prevent researchers from controlling certain key variables such as actual audience size for individual brand posts. As such, they cannot mitigate the effect of the Facebook newsfeed algorithm that influences the likelihood of a brand's message attracting engagement responses from consumers (Lee et al., 2014).

To avoid this limitation, we partner with a brand content provider (a Dublin-based radio station) to gain access to Facebook Insights, the background page analytics tool capturing real-time actions taken by brands and their consumers. The goal of this paper is to provide more definitive answers with regards to which rich media brand communication format (e.g. video and photo), and which interactive stimuli (various CTAs) influence online consumerbrand engagement as measured by clicks, likes, shares and comments (Facebook engagement metrics). We aim to contribute to the content marketing literature by addressing gaps in current knowledge and highlighting the effectiveness of these components of online marketing communications.

While brand managers cannot always control online brand portrayal in the face of user-generated content (UGC), they can manipulate media richness and interactivity cues to enhance consumer-brand engagement. Our real-world - observational setting enables us to focus on the challenges facing brand communicators in today's digital marketplace as marketers struggle to unlock the potential of social media sites for engaging fans. Our study also extends the body of academic knowledge in the area of communications by testing a model that relates media richness and interactivity cues with consumer-brand engagement. Our findings will help brands to devise content creation strategies which are most likely to generate consumer engagement.
The paper is organized as follows. First, we review the literature and clarify our various constructs to propose a model for consumer-brand engagement. Next, the methodology is outlined. Thereafter, we present our results and finally the discussion and implications of the findings are presented.

\section{Literature review}

\subsection{Engagement on social media}

While the marketing literature proposes that engagement is a three-dimensional concept incorporating cognitive, affective and behavioral responses (Brodie et al., 2011; Hollebeek et al., 2014), within the digital world engagement is often considered from a behavioral standpoint (Calder et al., 2009; van Doorn et al., 2010; Halaszovich and Nel, 2017). This study relies on Van Doorn et al.'s (2010, p. 253) definition of engagement as a behavioral manifestation toward a brand. It is perhaps reasonable that this conceptualization of engagement as a behavioral response has dominated marketing practice owing to the array of behavioral response metrics collated and reported by website management tools. For instance, from the early days of web advertising the click-through rate (CTR) became a focus for measuring engagement with online ads (Zhang and Mao, 2016; Fisher, 2009). The CTR offered marketers a more tangible measure of success to report to senior management over and above equivocal attitudes toward the brand or intentions to purchase. The higher the number of clicks relative to impressions signaled that consumers were highly attracted to the ad and demonstrated their engagement by clicking on it to access further information (Lohtia et al., 2003).

The mainstream use of social media such as social networking sites (SNSs) has made it necessary to adopt similar, more pertinent metrics of consumer-brand engagement in the digital environment today. SNSs are interactive websites that allow users to connect to others (i.e. brands) and engage with them in a variety of ways (Kaplan and Haenlein, 2010). Of late, one of the most commonly reported engagement metrics is the Facebook "like." This simple one-click social plugin enables consumers to indicate satisfaction or approval toward content on SNS (Swani et al., 2013; Gavilanes et al., 2018). Achieving a significant number of likes indicates that a post is interesting and popular, which further increases its ability to attract more likes (Sabate et al., 2014) in-turn promoting consumer engagement (Halaszovich and Nel, 2017; Pongpaew et al., 2017). Additional engagement metrics such as comments and shares further help to amplify a brand post's reach and signal its popularity to others (de Vries et al., 2012). By focusing on engagement as behavioral responses, the precise real-world actions of consumers measures how engaging brand communications through SNS such as Facebook really are.

This study utilizes measures of engagement reported by Facebook Insights. Facebook Insights is the back-end analytics tool used to support and track all activities on brand and other pages. It collates multiple data points on user interactions with the brand page, and reports among others the total numbers of clicks, likes, comments and shares recorded at the individual brand post level. These individual behaviors have been applied in previous studies to account for engagement (Berger and Milkman, 2012; Zhang and Mao, 2016; Halaszovich and Nel, 2017), whereas 
some other studies have used the same variables but labeled them popularity (de Vries et al., 2012).

In this study, two widely tested predictors of communications effectiveness, interactivity cues and media richness levels contained within the brand post (de Vries et al., 2012; Chua and Banerjee, 2015; Coyle and Thorson, 2001; Fortin and Dholakia, 2005), are used to understand how brand communication can influence engagement.

\subsection{Content features of social communications}

\subsubsection{Interactive cues in online communications}

Within the SNS environment, where marketer-control of a brand's image is potentially challenged by UGC (Fournier and Avery, 2011), marketers retain full control over the creation of the messages they post to the brand's profile page. Through control of what the message says, marketers can draw consumer attention to interactive cues embedded within the content of their native posts to induce consumer engagement behaviors. Interactive cues draw on the concept of interactivity from communications theory. Here interactivity refers to that which enables users to alter or make changes to content in a mediatedenvironment in real time (Steuer, 1992; Sundar and Limperos, 2013). Interactive cues leverage the interactivity inherent in social media platforms by allowing users to interact with content and with one another. For marketers creating brand messages that include an interactive cue, such as a voting mechanism or a request for feedback, highlights to users the interactive capabilities of the SNS medium (de Vries et al., 2012), and moreover, outline the favorable behavioral responses desired by marketers. The practice of embedding interactive cues within brand posts on social media resembles the more common practice of including CTAs in direct response advertising (Trappey and Woodside, 2005). Through embedding interactive CTAs into brand content, marketers may indicate their desire to directly converse with their consumers on social media, not to simply talk at them (Colliander et al., 2015). Thus, brand posts containing such signals of interactivity ought to activate greater consumer response than noninteractive or static brand posts.

The extant literatures in communications and advertising research however, fail to produce consistency of findings on the effects of such interactivity cues. Measures of interactivity are found to have positive, neutral and negative effects on advertising outcomes (Coyle and Thorson, 2001; Liu, 2003; Fortin and Dholakia, 2005; Liu and Shrum, 2002). Sundar and Limperos (2013, p. 515) suggest interactivity is a "doubleedged sword" as too much interactivity is as bad as none. Others including Fortin and Dholakia (2005) and Weiger et al. (2018) suggest "plateau effects" and potential diminishing returns when using interactive CTAs in the online advertising context. These authors find that increasing the degree of interactivity beyond a moderate level lowers consumers' behavioral intentions toward online ads.

Previous research outlined above, and including Coyle and Thorson (2001) and de Vries et al. (2012), delineate measures of interactivity along a continuum of high, medium and low levels. In this study, levels of interactivity are matched with the effortful response required of consumers to respond to the interactive CTA. Calls to click and like require a simple one click response action and thus are considered low-level interactivity (Sabate et al., 2014). Calls to share require consumers to spread electronic word-of-mouth (eWOM) with their contacts and are more demanding of consumers (Berger and Milkman, 2012), thus represents medium-level interactivity. Calls to comment demand consumers type a response and thus require additional investment of time and effort (Gavilanes et al., 2018), akin to high-level interactivity. From both a practical and a theoretical standpoint it is interesting to study interactivity in this way through the lens of interactive CTAs to uncover the extent to which a specific call to act influences a related behavioral response, and to determine interactivity level by the nature of the response required.

Hence the relationship between interactivity cues and consumer-brand engagement is considered here by examining whether a specific interactive call to act triggers a corresponding consumer engagement behavior, i.e. a click, like, share or comment:

H1a. Posts with an interactive CTA to click will generate more clicks than posts with no CTA.

H1b. Posts with an interactive CTA to like will generate more likes than posts with no CTA.

H1c. Posts with an interactive CTA to comment will generate more comments than posts with no CTA.

H1d. Posts with an interactive CTA to share will generate more shares than posts with no CTA.

\subsubsection{Rich media communications}

Media richness refers to the format in which the brand communication is presented. Media richness, also known as vividness, consists of two dimensions: breadth, or the number of senses activated by the message, and depth, concerning the quality of the presentation (Steuer, 1992). Rich media formats are thought to be highly engaging as the vividness of the presentation is more likely to stand out from the crowd and attract user attention (Lohtia et al., 2003). This is of particular importance in the SNS environment as the volume of content posted on social media sites is ever increasing. Branded posts are continually challenged to break through the clutter of the platform's newsfeed to create the opportunity for consumerbrand engagement on sites such as Facebook.

One potential way to attract attention to branded content is to use rich media that stimulate multiple senses simultaneously (Coyle and Thorson, 2001). Audio-visual posts, including dynamic animations (e.g. cartoons) and videos, stimulate the highest number of senses because of the presence of both visual and auditory cues, encouraging both systematic and heuristic information processing capabilities (Steuer, 1992). Furthermore, video-based communications offer a multiplicity of verbal and nonverbal cues such as facial expression and body language (Chua and Banerjee, 2015), and thus are taken here to represent high-level media richness. Colors, animations and contrasts found in photos and images offer moderate sensory stimulation (de Vries et al., 2012) and denote medium-level media richness. In contrast, text-only communications such as SMS or e-mail are static and nonsensory but require high levels of cognitive processing to attend to the arguments presented 
(Fortin and Dholakia, 2005). Text-only posts are considered here as nonrich, or lean, media. Hyperlinked text (links) is by comparison richer and more stimulating than plain text, but less so than images or video, and thus indicates low-level media richness.

In addition to breadth, the quality of the presentation also contributes to media richness effects. Marketers have access to much greater resources for creating professional-looking brand communications content compared to other SNS users. Marketer-produced content therefore ought to be slicker and more eye-catching than UGC. However, marketers must remember not to pursue an overly commercialized tone as "excessive commercialization" is likely to disengage consumers (Taylor et al., 2011; Weiger et al., 2018). SNS offer marketers the technological capability to host rich media content such as videos, links and photos, along with nonvivid plain text content. These varying rich media formats can be leveraged to stimulate consumer senses and attract attention. Together these insights lead us to postulate that consumers will be more engaged by content presented in rich media formats. This hypothesis is further delineated by engagement type:

H2a. A brand post presented in a rich media format (video, photo, link) will generate more clicks than posts containing no rich media (text only).

H2b. A brand post presented in a rich media format (video, photo, link) will generate more likes than posts containing no rich media (text only).

H2c. A brand post presented in a rich media format (video, photo, link) will generate more comments than posts containing no rich media (text only).

H2d. A brand post presented in a rich media format (video, photo, link) will generate more shares than posts containing no rich media (text only).

The conceptual model guiding our research study is reproduced in Figure 1.

\subsubsection{Control variables}

In addition to engagement measures, the size of the audience reached by each brand post is controlled. Audience reach is highly irregular on Facebook, with the vast majority of Facebook

Figure 1 Conceptual model

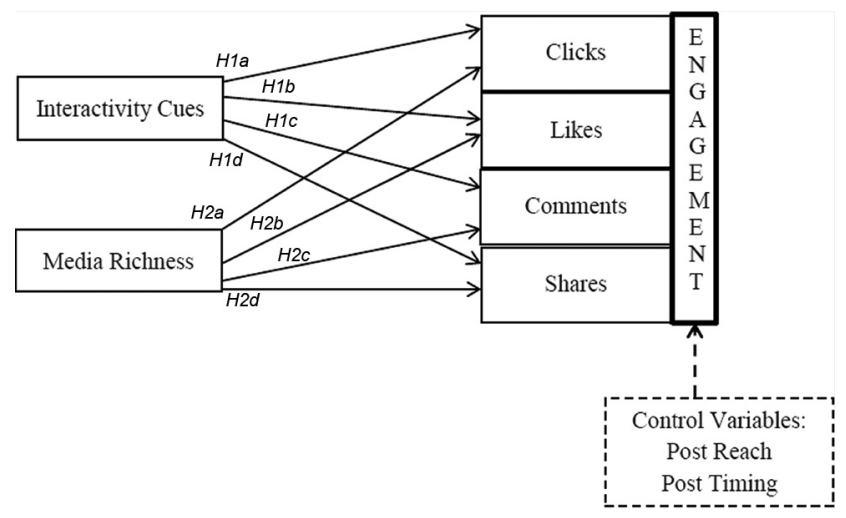

users accessing brand updates through their newsfeeds (and not by visiting the brand page) (Lipsman et al., 2012). Nevertheless, previous studies focusing on content marketing on Facebook have used the size of the brand's fan-base, indicated by the total number of consumers who have liked the brand page, as a proxy to control for audience size (de Vries et al., 2012; Swani et al., 2013; Sabate et al., 2014; Tafesse, 2016). This is potentially erroneous, as it does not account for the vicissitude of the Facebook algorithm. As many industry reports demonstrate, there is no correlation between the number of page fans and post reach. The newsfeed algorithm is dependent on hundreds of factors and the liking pattern now only plays a minor role[1]. As such the size of the audience reached by each brand post has a greater potential influence on engagement with the brand's content than the raw number of brand page "fans." This is further accentuated by the network effects of SNS platforms as the audience size grows because of popular content being spread among friend networks (nonfans) as more people engage with the brand posts (Swani et al., 2013; Lipsman et al., 2012).

Another factor with implications on the newsfeed algorithm, the timing of a brand post, provides another control. As "always on" media, SNS enable brands to schedule posts throughout the day/week and inevitably, the audience size is going to fluctuate between peak and off-peak browsing times. Furthermore, the instance of engagement behaviors occurring is likely to differ between weekdays and weekends as users have more or less time to process brand post information and engage with posts from favored brands (de Vries et al., 2012; Sabate et al., 2014). Accordingly, to conduct a thorough analysis of consumer-brand engagement, it is pertinent to actively control for the actual number of people reached by, as well as the timing of, a brand's social media posts.

\section{Methodology}

The world's most popular social networking site, Facebook, is the setting for this study. This real-world setting enables us to focus on the challenges facing brand communicators in today's digital marketplace. Data are gathered by way of Facebook Insights, the background page analytics tool capturing realtime actions taken by brands and their consumers. Facebook Insights is a digital tool, which is only accessible to the administrator of a specific Facebook Page. The researchers were fortunate to gain full administrative access to the brand page under consideration. Among the many metrics provided, Facebook Insights provides a complete and accurate overview of how Facebook users interact with a brand post. Namely, the data investigated included post timing, clicks, likes, comments and shares, as well as data on each post's reach, i.e. the total number of people who were shown a specific post and total reach, i.e. the total number of people who saw any kind of activity from the page. This study considers the efficacy of certain brand-controlled content components derived from communications theory and uncovers how consumer engagement may be leveraged through the strategic use of these components.

\subsection{Sample}

To test our hypotheses 757 Facebook-based brand posts from one brand partner, an Irish radio station, over a 15-week period 
are analyzed. This brand partner consistently ranked within the top five "most engaging" Irish brands according to social media analytics company SocialBakers.com (2015) in the six-month period preceding this research. The media and entertainment industry has faced enormous disruption because of the advent of Web 2.0 and growth in the production of UGC as a source of entertainment (Chipp and Chakravorty, 2016; PwC, 2015). To gain attention in this industry and procure online engagement, brands are increasingly challenged to create content that adds value for consumers. Regular posting of updates is commonplace to meet the demands of today's digital content consumers. Our brand partner is an active user of the Facebook SNS, regularly producing and disseminating content designed to engage its youthful audience base of 18-30-yearolds. This particular consumer group is heavily reliant on social media such as Facebook, designating it their preferred source for news and entertainment updates (Boczkowski et al., 2018; Warc, 2016).

\subsection{Coding variables and procedures}

\subsubsection{Interactivity cues}

Interactivity cues such as calls-to-act can be used by marketers to solicit certain response or behavioral actions from their audiences. In this study, various interactive CTAs are coded to test their efficacy in motivating specific behavioral engagement outcomes in line with previous literature (de Vries et al., 2012; Stephen et al., 2015).

Low-level interactivity cues include clickbait and likebait. Clickbait CTAs, for example, "Click here" or "Find out more," are designed to generate clicking behaviors, while likebait CTAs, for example, "Like our new logo," are designed to drum up likes. While these CTAs demand little response effort from consumers via a simple one click behavioral action (Swani et al., 2013), they are also useful mechanisms for marketers as they can motivate particular marketer-desired engagement behaviors such as content discovery and website referral, while also signaling a brand post's popularity to other audience members (Sabate et al., 2014; Stephen et al., 2015).

Moving beyond one-click behaviors, two or more clicks are required to share branded content with one's friend network. Sharing mechanisms such as pass along CTAs, for example, requesting consumers to "Share this with your friends," are designed to generate eWOM using the network effects of the SNS by amplifying the size of the brand post's audience (Schulze et al., 2014; Stephen et al., 2015; Tellis et al., 2019). Pass along CTAs are more demanding than simple one-click response behaviors as consumers can choose to share with everyone in their network simultaneously, or to pass content along to a select few recipients. As such pass along CTAs here represent medium-level interactivity cues.

Finally, interactive CTAs in brand posts that require the most effortful response actions from the audience are classified as high-level interactivity cues. Asking the audience to respond to a direct question requires consumers to formulate their thoughts and articulate a response, which is undoubtedly much more demanding than clicking or sharing actions (de Vries et al., 2012; Gavilanes et al., 2018). These question CTAs, such as "Tell us what you think" and are designed to generate commenting behaviors that enable marketers to solicit feedback from consumers and engage in dialogue and conversation with them (Gavilanes et al., 2018; Swani and Milne, 2017).

Lastly, there are some brand posts that do not include CTAs or interactive cues and these are coded as no CTA, acting as the base category for comparison in this study.

\subsubsection{Media richness}

Brand posts are also categorized along three levels of media richness in line with previous research (Coyle and Thorson, 2001; Fortin and Dholakia, 2005; de Vries et al., 2012). Media richness theory contends that the level of richness increases as the number of senses activated by the content increases. In this vein, Steuer (1992) proposed that posts containing contrasting colors or imagery are more vivid and thus richer than posts containing text-only elements. Similarly, dynamic animations are more stimulating to the senses than static pictures. Furthermore, posts containing hyperlinks, which enable the user to discover more content by clicking on those links, are also considered richer than plain text posts (Lohtia et al., 2003).

Therefore, we postulate that posts containing hyperlinks represent low-level richness, photo-based posts symbolize medium-level richness and video-based posts comprising audio-visual presentations and dynamic animations signify the highest level of media richness as they stimulate the most senses. Again for comparison purposes, posts containing plaintext do not include any rich media elements and represent the base category in the subsequent analysis. The variables are summarized in Table I below.

Four trained coders coded approximately 20 per cent (150) of the posts. A post was coded 1 if a CTA to like or click was present (low interactivity), 2 if a CTA to share was present (medium interactivity), 3 if a CTA to comment was present (high interactivity) and 0 otherwise. Figures for our control variables post timing and audience size were recorded from Facebook Insights. Post timing was coded 0 if the posts occurred during business hours (Monday-Friday, 9 a.m.-6 p. $\mathrm{m}$.), and 1 otherwise. Frequencies are reported in Table I above. The associated intercoder reliabilities were all greater than the acceptable 0.8 cut-off level (Cohen's kappa $=0.83$; Fleiss' kappa $=0.82$; Krippendorff's alpha $=0.83$ ). Two further coders coded the total sample of 757 posts, also producing acceptable intercoder reliabilities (Cohen's kappa = 0.89; Scott's $\mathrm{Pi}=0.89$; Krippendorff's alpha $=0.89$ ). Disagreements were resolved through discussion. For media richness, post type is systematically tagged as containing a link, photo, video or status update (text) within the Facebook Insights analytical reports and these categorizations were adopted in this study. A spot check of 50 posts was carried out

Table I Interactivity and media richness variables

\begin{tabular}{ll}
\hline Interactivity & Media richness \\
\hline No CTA & Text \\
Clickbait ("Click here") & Link \\
Likebait ("Like this") & \\
Pass along & Photo \\
("Share with your friends") & \\
Question & Video \\
(Discussion, feedback) & \\
\hline
\end{tabular}


prior to adoption to verify the accuracy of this tagging system, and no discrepancies were identified.

\subsection{Data analysis}

Our engagement metrics consist of counts of clicks, likes, comments and shares attributed to each brand post, indicating the number of times it was engaged with through each response mechanism. Count data such as these follow a Poisson distribution rather than a normal distribution (Hilbe, 2014) as Poisson adjusts for the probabilities of positive-only integers. Furthermore, a proportion of our sampled brand posts achieved very high response levels across all engagement metrics as these posts went "viral", and attracted amplified attention and engagement in the social media environment. This created a positive skew in the distribution of each count outcome whereby the Poisson assumption of equidispersion was violated for the four outcome models [all Chi-square statistics $\left(\chi^{2}\right)>1$ ]. A negative binomial (NB2) model is thus adopted (Coxe et al., 2009) as it is less restrictive than a Poisson model, and is commonly used as an alternative to model overdispersed count data (Hilbe, 2014). The negative binomial model (NB2) used to explain our four dependent engagement variables (clicks, likes, comments and shares) is:

$$
\begin{aligned}
\mathrm{y}_{\mathrm{ij}}= & \alpha \exp \left(\sum_{\iota=1}^{757} \beta 0+\beta \operatorname{richej} X 1 j+\beta \text { inter }_{f j} X 2 j\right. \\
& \left.+\beta \text { richej } * \beta \text { inter }_{f j} X 3 j+\beta \text { reachgj } X 4 j+\beta \text { timehj } X 5 j\right)
\end{aligned}
$$

where:

$\mathrm{y}_{\mathrm{ij}} \quad \mathrm{y}_{1 \mathrm{j}}$ is the number of clicks per brand post $\mathrm{j}$, $y_{2 j}$ is the number of likes per brand post $j$, $y_{3 j}$ is the number of comments per brand post $j$, and $y_{4 j}$ is the number of shares per brand post $j$;

$\beta$ rich $_{\mathrm{ej}} \quad=$ the regression coefficient indicating the level of media richness e at brand post $j$ (base $=$ none);

$\beta$ inter $_{\mathrm{fj}}=$ the regression coefficient indicating the level of interactivity $f$ at brand post $\mathrm{j}$ (base $=$ none);

$\beta$ rich $_{\mathrm{ej}}{ }^{*} \beta$ inter $_{\mathrm{fj}}=$ the regression coefficient for the interaction term for level e of media richness * level f of interactivity for brand post $j$;

$\beta$ reach $_{j} \quad=$ the reach of brand post $\mathrm{j}$ (control variable); and

$\beta$ time $_{j} \quad=$ the timing of brand post $\mathrm{j}$ (control variable).

Each of the four dependent variables (clicks, likes, comments and shares) are modelled separately to more accurately measure the effects of interactive CTAs and media richness on specific consumer engagement behaviors with brand posts. Tests of significance (likelihood ratio chi-square test) indicate that each model is significant at the 0.001 level (Hilbe, 2014). Moreover, each negative binomial model shows better "goodness of fit" statistics over and above its comparative Poisson model (Coxe et al., 2009). Table II outlines the
Table II Goodness-of-fit statistics

\begin{tabular}{lcccc}
\hline NB2 model & Deviance & Pearson $\chi^{2}$ & Likelihood ratio $\chi^{2}$ & Sig. \\
\hline Clicks & 1.178 & 0.713 & 876.112 & 0.000 \\
Likes & 1.216 & 1.093 & 927.715 & 0.000 \\
Comments & 1.243 & 1.168 & 549.734 & 0.000 \\
Shares & 1.128 & 1.139 & 746.511 & 0.000 \\
\hline
\end{tabular}

"goodness of fit" statistics for each of the four negative binomial models.

Negative binomial regression with maximum likelihood estimation (MLE) is used to test the direct effects of interactivity and media richness on consumer-brand engagement outcomes, as well as to examine content combinations. For ease of interpretation the exponentiated beta coefficients, $\exp (\beta)$, from the regression results are presented in Table III and discussed hereafter.

\section{Findings and discussion}

\subsection{Interactivity effects}

The relationship between interactivity cues and engagement is as anticipated. We propose that interactivity cues (CTAs) are positively related to engagement outcomes as greater brand post interactivity ought to be more attractive to consumers. By explicitly offering consumers opportunities to directly interact with brand content, engagement outcomes such as clicks, likes, comments and shares should increase. The results confirm that posts containing interactivity cues are more effective in attracting greater numbers of clicks, likes, comments and shares compared to non-interactive content. This is in line with previous studies by Coyle and Thorson (2001) and Liu (2003) who also found brand post interactivity increased consumer response to brand communications.

However, where our findings differ is in uncovering that the inclusion of specific interactive cues aimed to encourage particular engagement behaviors lead to an increase in the number of those explicit behaviors being generated. This finding is consistent across all types of interactive CTAs and offers support for hypotheses $\mathrm{H} 1 \mathrm{a}, \mathrm{H} 1 \mathrm{~b}, \mathrm{H} 1 \mathrm{c}$ and $\mathrm{H} 1 \mathrm{~d}$. Our results show that the inclusion of clickbait CTAs (low-level interactivity cues) increase the number of clicks by over five times the amount generated by non-interactive brand posts (H1a: 5.171, $p<0.05)$. Similarly, likebait CTAs increase liking behaviors by more than fourfold (H1b: 4.412, $p<0.05$ ). Requesting consumers to pass along content to their peers (medium-level interactivity cues) is a particularly effective means of increasing shares of branded content (H1c: 57.253, $p<0.001$ ), whereas asking direct questions (high-level interactivity cues) to solicit consumer feedback via comments is also highly compelling ( $H 1 d: 1.574 \mathrm{E}+11, p<0.001)$. In essence, marketers are able leverage the interactive capability of the SNS medium to guide consumer-brand engagement by providing consumers with explicit interactive cues to facilitate specific, marketer-desired engagement behaviors.

Indeed, the study also shows that including an interactive call-to-act to encourage one type of engagement behavior has a near universal effect in increasing all engagement behaviors. For example, a brand post which contains a CTA to comment not only usefully increases comments, but also increases clicks, 
Table III Negative binomial regression results

\begin{tabular}{|c|c|c|c|c|c|}
\hline Facebook post variables & Description & Clicks & Likes & Comments & Shares \\
\hline \multirow[t]{4}{*}{ Interactive cues } & Question & 9.855 & 0.655 & 4.154 & $1.397 \mathrm{E}+10$ \\
\hline & Pass Along & 6.122 & 5.373 & 57.253 & $1.574 \mathrm{E}+11$ \\
\hline & Click-/Like-bait & 5.171 & 4.412 & 0.906 & $1.023 E+11$ \\
\hline & No CTA (Base) & - & - & - & - \\
\hline \multirow[t]{4}{*}{ Media richness } & Video & 24.165 & 3.814 & 4.206 & $2.097 E+11$ \\
\hline & Photo & 11.981 & 15.114 & 2.870 & $2.605 E+11$ \\
\hline & Link & 18.652 & 3.202 & 3.963 & $1.481 \mathrm{E}+11$ \\
\hline & Text (Base) & - & - & - & - \\
\hline Post reach & & 1.000 & 1.000 & 1.000 & 1.000 \\
\hline Post timing & & 1.092 & 1.263 & 1.151 & 1.243 \\
\hline Constant & & 46.611 & 16.810 & 6.251 & $2.560 \mathrm{E}-11$ \\
\hline \multicolumn{6}{|l|}{ (Negative binomial) } \\
\hline$N=757$ & Ancillary parameter & 0.951 & 1.286 & 1.767 & 1.990 \\
\hline
\end{tabular}

likes and shares on that brand post too. Yet surprisingly it is not necessarily the specifically curated call-to-act that has the largest influence on the corresponding engagement behavior. For instance it is the interactive CTA to pass along content that generates the largest number of likes, comments and shares. Furthermore, and counter-intuitively, asking consumers to engage in the simplest and least-effortful form of interactivity, i.e. clicking on content via the inclusion of clickbait CTAs, has the weakest effect on generating clicks of any of the interactivity cues proposed here. Perhaps what these findings indicate is a rising tide of engagement; whereby any invitation to encourage consumers to participate and engage leads to an increase in all forms of brand post engagement.

Previous research has proposed that medium level interactivity may be optimal for generating the most consumerbrand engagement (Fortin and Dholakia, 2005; Weiger et al., 2018). This rationale was put forth as high-level interactivity may be considered too demanding of consumers' time and effort. Our findings are broadly in line with this proposition and show a positive and significant relationship between mediumlevel interactivity cues (pass along CTAs) and brand post engagement across all four engagement behaviors. Fortin and Dholakia (2005) recommended an optimum level of interactivity to match interactivity demands with consumer involvement and website experience. Similarly, we find that pass along CTAs, which require action but are not overly demanding, have the greatest impact on generating consumer engagement behaviors.

Importantly consumers on Facebook voluntarily choose to connect their profiles with a brand's to become "fans" of that brand's page (Mangold and Faulds, 2009). This voluntary action enables two-way brand-consumer communications and suggests a heightened level of consumer-brand involvement (Chipp and Chakravorty, 2016). The positive relationships found in this study between interactivity cues and consumerbrand engagement suggests that providing consumer "fans" with direct opportunities to interact with brands can be highly beneficial. The motivations for these findings may be related to consumers' desires to affiliate more closely with a certain favored brand or to feel a greater sense of community involvement with other brand fans on the SNS
(Mangold and Faulds, 2009; Tafesse, 2016). Acknowledging these motivations may prove fruitful for future content marketing strategy design also.

Overall, our findings are very positive and provide somewhat of a counterbalance to research by Tsai and Men (2013) and Creamer (2012) which proposes that consumers are not as actively engaged with brands on Facebook as marketers would like. Our research shows that consumers do actively engage with branded content, and even show preferences for the more time-consuming opportunities to directly engage with favored brands through Facebook.

\subsection{Media richness effects}

The relationships between consumer-brand engagement and rich media content are also as predicted, showing rich media to have a positive and significant influence on engagement. The proposed effects of media richness on the engagement behaviors of clicks, likes, comments and shares are verified in this study, offering full support for our hypotheses $H 2 a, H 2 b$, $\mathrm{H} 2 \mathrm{c}$ and $\mathrm{H} 2 \mathrm{~d}$. Across all levels of media richness, brand posts in rich media formats attract more engagement than brand posts lacking media richness. Sensory stimulation has previously been found to heighten attention to a piece of content and subsequently induces greater consumer response (Berger and Milkman, 2012). Building on this, and in line with media richness theory, we find that rich media formats which activate a greater number of senses (e.g. video) are highly successful in generating increased consumer-brand engagement outcomes.

On average, a video will attract more than 24 times the number of clicks attained by text-based posts $(24.165, p<$ 0.001). Video content is also responsible for attracting the highest number of comments of any rich media type, over 4 times more than textual content $(4.206, p<0.001)$. Thus, videos are adept at generating engagement, from the simplest to most complex response behaviors. Moreover, branded content in photo format attracts the most likes and shares. Photos are "liked" more than 15 times more often than plain text content (15.114, $p<0.001)$, whereas photos are also "shared" much more often than text-based status updates $(2.605 \mathrm{E}+11, p<$ $0.001)$. 
In general, the findings suggest that visually stimulating content (photos and videos) is more engaging than less rich, or lean, content. Interestingly, brand posts containing photos performed better on average than video posts in terms of increasing the numbers of likes and shares generated, while also positively influencing clicking and commenting behaviors. In particular, eWOM generated through the sharing of photobased posts was higher on average than video-based posts. While some recent research activity is concerned with the importance of viral video (Berger and Milkman, 2012; Porter and Golan, 2006), photo-sharing activities have received relatively little research interest. The findings of this study should have direct implications for content marketing which is increasingly focused on the production of social video content (Content Marketing Association, 2016). Previous research suggests that video content may be considered more intrusive, thus likely to detract from users' online flow experiences and increase information overload (Fortin and Dholakia, 2005). Perhaps users are less inclined to share videos with their friends because they are more burdensome in the time and effort required to process compared to photos. Thus, a greater understanding of the relative impact of photo-based content compared to video-based content on influencing consumerbrand engagement is pertinent, given the additional time and cost resources required to create video content for social media channels.

In addition, our findings show rich media posts are not very influential in generating commenting behaviors. Perhaps this indicates that while consumers are happy to signal their interest (clicking) and approval (liking) for rich media posts, they are less inclined to get involved in a discussion or conversation surrounding these posts. Two-way communications undoubtedly are more demanding of consumer efforts, and thus may not be seen by consumers as worth their time. Another possible explanation is that an argument which is worth commenting requires a lengthy development (i.e. text) contrary to videos and pictures which could possibly trigger some emotional reaction for which words (comments) are of no help.

Nevertheless, we find that the inclusion of rich media in Facebook-based content marketing strategies appears to be important for encouraging additional clicking, liking, commenting and sharing behaviors. The results of our hypotheses tests for the effects of interactivity and media richness on consumer engagement behaviors are summarized in Table IV.

Table IV Results of hypotheses testing

\begin{tabular}{llll}
\hline Independent variables & \multicolumn{2}{l}{ Hypotheses } & Outcome \\
\hline CTAs & $H 1 a$ & CTAs \& clicks & Supported \\
& $H 1 b$ & CTAs \& likes & Supported \\
& $H 1 c$ & CTAs \& comments & Supported \\
& $H 1 d$ & CTAs \& shares & Supported \\
Media richness & $H 2 a$ & Richness \& clicks & Supported \\
& $H 2 b$ & Richness \& likes & Supported \\
& $H 2 c$ & Richness \& comments & Supported \\
& $H 2 d$ & Richness \& shares & Supported \\
\hline
\end{tabular}

\subsection{Interaction effects}

Moreover, we delved a little deeper into these relationships by examining the interaction effects of media richness and interactivity on consumer-brand engagement behaviors. We held no a priori expectations of which content combinations would manifest as the most engaging and instead aim to uncover effective content marketing pairings. We find that the combination of clickbait cues coupled with video format attracts more clicks than similar clickbait cues in either photo (18.04.72, $p<0.05)$ or text $(2596.09, p<0.05)$ formats. Clickbait presented in link format also receives more clicks than photos (1251.51, $p<0.001)$ or text (2042.88, $p<0.001)$. These findings suggest that clickbait is most effective when included alongside a media format that offers consumers something specific to click, for instance a hyperlink or a video "play" button. Surprisingly we find that when photo format is used, the most effective interactive element to include to drive clicking behaviors is a question.

Interestingly, we find likebait tactics to be largely ineffective for enhancing likes regardless of the rich media format used. This suggests that it is more difficult to encourage consumers to "like" branded content than to click on it, perhaps owing to consumer's name being attributed to the "like" and therefore visible to their friends on their social network contacts list. Pass along requests however in photo format tend to generate more likes than similar interactive cues in video $(365.49, p<0.001)$ or link formats $(407.81, p<0.001)$.

In relation to enhancing commenting behaviors, asking questions to encourage consumer feedback attracts more comments when presented in photo format compared to video (66.15, $p<0.05)$, link (55.03, $p<0.05)$, or text $(45.18, p<$ $0.05)$ formats. Pass along interactive cues are also most effective at generating comments when coupled with photobased posts in contrast to videos $(380.45, p<0.001)$, and links (546.17, $p<0.001)$. Text-based content is least likely to bring about commenting behaviors, and even less so when no interactive CTA is included in the post (video: -53.36 , photo: -31.12, and link: -49.32 , all $p<0.001)$. Lastly sharing behaviors are best encouraged by the content combination of pass along requests in photo format, outperforming video (40.66, $p<0.001)$, link (40.75, $p<0.001)$, and text formats (34.14, $p<0.05)$. We find both text-based formats and noninteractive brand posts are largely ineffective at generating shares of branded content. In sum, branded content appears to be most engaging when rich media formats and interactive cues (CTAs) are used in combination.

\section{Implications for content marketing theory and practice}

The findings outlined above suggest marketers are perhaps more in control of activating consumer-brand engagement behaviors than previously highlighted by the extant literature. In particular, the strategic manipulation of controllable content components, media richness and interactivity cues, are shown here to influence and enhance consumer-brand engagement in the form of four behavioral responses: clicks, likes, comments and shares. These findings contribute to the communications and engagement literatures. First, we contribute to communications theory and add to knowledge of interactivity 
effects by demonstrating that interactive cues are effective in producing consistent positive effects on engagement with brand communications. The inclusion of an interactive CTA increases consumer engagement for each behavior measured here, including both one-click (click, like) and more effortful behaviors (shares and comments). Accordingly, interactive cues such as CTAs effectively enhance consumer-brand engagement behaviors. This is in contrast to previous findings by both Fortin and Dholakia (2005) and Weiger et al. (2018) which suggest that interactivity effects plateau above a moderate level.

More precisely, our study identifies that the inclusion of certain instructive CTAs leads to an increase in specified corresponding behavioral outcomes. Thus rather than chasing broad consumer engagement, marketers may be better off focusing efforts on eliciting those behavioral responses which are in line with desired social media marketing campaign goals. For instance if a marketing campaign seeks feedback from customers, including a call-to-comment will beneficially increase the feedback solicitation process. As such to stimulate consumers to engage with a brand on SNS, it seems the easiest route is to simply ask for their engagement. Also marketers have the ability to facilitate and curate the engagement responses of consumers through the inclusion of an instructive, interactive CTA to invite a specified response. These two findings are our primary contributions to the communications literature because they highlight the malleability of content marketing design for enhancing consumer-brand engagement through the adoption and adaptation of interactivity in the form of CTAs. Furthermore, explicitly highlighting the interactive capabilities of the SNS to consumers appears to draw attention to those capabilities, and perhaps it is this which encourages consumers to interact with those interactive features to engage with the brand. This insight requires further research to clarify the role of interactive CTAs in relation to consumer-brand engagement on SNS. Nevertheless, we have demonstrated a positive consistency in our interactivity results previously lacking in the literature to date.

Similarly, we further advance knowledge in the area of communications and contribute to media richness theory by uncovering that rich media formats consistently outperform lean media formats in their ability to attract consumer-brand engagement. Heightened sensory stimulation via rich media formats encourages consumers to click, like, comment and share more frequently, which adds to the claim that rich media are more adept at attracting attention in the crowded social media sphere (Chua and Banerjee, 2015; de Vries et al., 2012). While our findings here corroborate those of Steuer (1992), we further reveal that medium-level richness (photo) is comparable in its effectiveness to high-level richness (video) at driving consumer-brand engagement. This contrasts with media richness theory, which asserts that richer media are more engaging. Instead we find photo-based posts and video-based posts are useful for eliciting different engagement behaviors. Interestingly photo-based posts (medium-level richness) attract the most likes and shares from consumers, which challenges conventional social media wisdom preferring video content and reiterates the importance of continued research in this field. Accordingly, a picture may be worth a thousand words, but in this instance it is also as valuable as a video. Perhaps the additional time and effort required of consumers to process video-based content detracts from their engagement with it, in line with the concept of cognitive overload from information processing theory (Petty and Cacioppo, 1986; Fortin and Dholakia, 2005). This insight again illustrates marketers' ability to shape content marketing design to elicit desired engagement responses from consumers.

Lastly, we also add to the engagement literature by delving deeper into the behavioral dimension of consumer-brand engagement and highlight that different engagement responses may be activated through strategic marketer manipulation (van Doorn et al., 2010). We demonstrate that engagement behaviors manifest differently as consumers respond to a variety of marketer-created and controlled stimuli. As such, marketers can mold the success of their campaigns by engineering branded content in line with desired campaign outcomes. This highlights the necessity of understanding the varying facets of consumer-brand engagement behavior to inform both marketing theory and practice.

Our findings also offer a number of practical and managerial implications concerning content marketing creation. We organize the practical implications of our research by the behavioral outcome (clicks, likes, shares and comments) desired by brand managers.

\subsection{Clicks}

Generating clicking behaviors is important as it increases website referral for the brand (Stephen et al., 2015). Including clickbait tactics, such as specific calls-for-clicks translates into more clicks on branded content. Furthermore, the inclusion of other interactive CTAs also piques consumer interest enough to want to discover more about the brand. In particular asking questions tends to drive more clicks than clickbait. This means that if a brand manager wants to encourage Facebook users to visit its website, it may be better off to ask them questions to raise their curiosity rather than simply instruct them to click to follow a link.

In general, all rich media formats encourage more clicks than static plain-text content, but video-based content has the greatest impact on encouraging clicking behaviors, thus videos are the best source of encouraging content discovery. This suggests that brands aiming to build awareness or drive website referral may benefit most from investing in social video content.

\subsection{Likes}

Liking brand content enables consumers to show their acceptance or preference for a piece of content, and many likes indicate the popularity of a post (de Vries et al., 2012). In terms of interactivity, clickbait, pass along requests, and direct questions are all useful in increasing post likes. With regard to media richness, photo-based content is by far the most effective rich media format for increasing post likes. Therefore, if popularity, broad reach and eWOM are important marketing campaign goals, then marketers ought to invest in quality imagery and photo-based content. This finding indicates that SNS users may not prefer videos after all, and puts the onus on marketers to create effective content in the format preferred by their online "fans". 


\subsection{Comments}

Through commenting behaviors, brand managers solicit feedback from consumers. Further, commenting enables twoway conversation and community building. Pass along requests and asking direct questions are both effective interactive cues to include in brand posts to increase the number of consumer comments. Thus, marketers seeking feedback and dialogue benefit most from direct interaction with consumers. However, the "richness" of the media will play only a small role in the overall volume of comments generated.

\subsection{Shares}

Sharing behaviors are most often associated with "viral" content and as such, they are instrumental in brand awareness campaigns. The inclusion of interactive content components is effective at increasing shares. Unsurprisingly asking consumers to pass along content increases the total number of sharing actions taken. Rich media content is also more inclined to induce sharing activity over and above plain-text brand posts. Interestingly, photo-based posts are more likely to be shared than video-based posts. Again this reinforces that broad reach and eWOM are most likely to accrue with photo-based posts, heightening the importance of matching campaign goals to content marketing design decisions.

Together these insights into consumer engagement behaviors show that consumers are actively contributing to SNS brand pages. Strategically varying the levels of interactivity cues and media richness can help achieve social media marketing campaign goals including content discovery, website referral, popularity, feedback, and eWOM activities (Stephen et al., 2015) (Table V).

\section{Conclusion}

This study attempts to address how digital marketers can adapt and leverage certain elements of brand communications to enhance consumer-brand engagement on Facebook. It considers two widely used concepts within both communications and advertising literatures: interactivity cues and media richness, and in doing so reveals consistent positive effects of employing these.

Three primary conclusions may be drawn. First, our realworld observations based on Facebook Insights more solidly confirm the somewhat inconsistent findings of previous studies with regards to media richness and interactivity cues. Rich media content does increase consumer-brand engagement. Consumers of online content click, like, comment on and share rich brand content more than static or lean content. We also show that there is a near universal effect of CTAs on each of the four engagement variables measured here (clicks, likes, shares

Table V Summary of best message format per desired behavioral outcome

\begin{tabular}{lll}
\hline $\begin{array}{l}\text { Desired behavioral } \\
\text { outcome }\end{array}$ & CTA & Media richness \\
\hline Click & Ask a question & Video \\
Likes & Call to action to click & Photo \\
Comments & Ask a question & Not determined (all equal) \\
Share & Ask to share & Photos + videos \\
\hline
\end{tabular}

and comments) such that the inclusion of a single CTA simultaneously boosts all consumer engagement behaviors. Asking for engagement acts as a powerful tool for success.

In the discussion, we also uncover some new and counter intuitive findings. For example, in contrast to the growing practitioner focus on viral video effectiveness (Chua and Banerjee, 2015), this study shows photo-based content to be more engaging than video content. In fact, video-based content failed to attract more likes or more shares than photos, two widely used indicators of overall content success (Berger and Milkman, 2012; Sabate et al., 2014). With regards to specific calls-to-action, calls-to-click, considered here as low-level interactive cues asking consumers to engage in the simplest form of interactivity, have the weakest effect on generating clicks of any of the interactivity cues proposed here. Perhaps this suggests that consumers are more interested in engaging with brands directly on the SNS rather than linking through to brand websites and thus removing themselves from the more social SNS ecosystem.

Thirdly, achieving the elusive "viral" success of social media through increasing eWOM sharing activities is positively related to the inclusion of interactivity cues and media richness components, with photos performing best. Together these insights strongly suggest the importance of brand managers delving into their own data sources to derive data-driven decisions concerning the specific preferences and engagement behaviors of their own consumers. Trends in increasing budgetary spend on viral video content creation (eMarketer, 2015) are all well and good if the conditions necessary for a brand's viral success have been identified to include preferences for video consumption. However, if, as this study shows, photos are shared more often than videos then the current allocation of social media marketing funds may be sub-optimal. It is imperative that marketers optimize their content for success.

Lastly, this study is subject to limitations, which may stimulate future research. The sampled posts pertain to one media and entertainment brand and are thus concentrated within one industry. Brands within the media and entertainment industry are very active at producing content on Facebook, and are highly concerned with seeking out consumer engagement on this platform. As such, the more experiential nature of this brand means it may face very different challenges compared to more utilitarian consumer brands. Therefore, we caution the generalizability of our findings as Schulze et al. (2014) have identified the fallacy of adopting a "one-size-fitsall" approach to social media marketing. They highlight the detrimental effect of undertaking the wrong promotional campaigns relative to the type of products offered by brands. Consequently, additional research is necessary to expand the scope of this research to include other industries and products/ services. Perhaps video content will prove more effective for utilitarian products, which may benefit from the power of demonstration. In addition, research may reveal differences in content component efficacy for manufacturer versus retail brands, or luxury versus non-luxury brands. This would add to the growing body of knowledge on content marketing, which already shows differences between goods and services (Swani and Milne, 2017). Furthermore, we did not consider the role of message appeal within the content. While understanding the 
effects of format decisions such as interactivity and media richness are worthwhile, the engagement effects attributed to the message appeal cannot be ignored. Some work has begun examining the role of information and emotion in brand messages for social media (Tellis et al., 2019; de Vries et al., 2012; Araujo et al., 2015; Berger and Milkman, 2012), but further research linking these to media format type and interactive cues would provide a more holistic understanding of effective content marketing design.

In addition the sentiment of consumer engagement was not investigated, assuming that the act of engaging represented a positive reaction to brand content. Future research could delve deeper into the valence of the comments attributed to brand posts and additional "reactions" recorded beyond likes (e.g. sadness, anger) which can now be examined via Facebook Insights to determine if consumers engage with brands in a positive or negative manner on SNS (Araujo et al., 2015). Lastly, this study is set within the Facebook SNS, which may limit the implications and generalizability of our findings. It would be interesting to extend this work to other social media sites which are more visual (e.g. Instagram, YouTube) or more textual (e.g. Twitter) in nature to determine whether different effects for visually rich content emerge across platforms. Perhaps consumers are motivated to engage differentially depending upon the pervading nature of the content featured on the platform (Voorveld et al., 2018). While this study provides some beneficial insights into media richness and interactivity cues for content marketing design, there are many fruitful avenues for future research to explore.

\section{Note}

1 https://blog.hubspot.com/marketing/how-algorithm-worksfacebook-twitter-instagram (accessed 13 December 2017).

\section{References}

Araujo, T., Neijens, P. and Vliegenthart, R. (2015), "What motivates consumers to re-tweet brand content? The impact of information, emotion, and traceability on pass-along behavior", Fournal of Advertising Research, Vol. 55 No. 3, pp. 284-295.

Berger, J. and Milkman, K.L. (2012), "What makes online content viral?”, fournal of Marketing Research, Vol. 49 No. 2, pp. 192-205.

Boczkowski, P.J., Mitchelstein, E. and Matassi, M. (2018), "News comes across when I'm in a moment of leisure': understanding the practices of incidental news consumption on social media", New Media E Society, 1461444817750396, Vol. 20 No. 10, pp. 3523-3539.

Brodie, R.J., Hollebeek, L.D., Juric, B. and Ilic, A. (2011), "Consumer engagement: conceptual domain, fundamental propositions, and implications for research", Fournal of Service Research, Vol. 14 No. 3, pp. 252-271.

Calder, B.J., Malthouse, E.C. and Schaedel, U. (2009), "An experimental study of the relationship between online engagement and advertising effectiveness", fournal of Interactive Marketing, Vol. 23 No. 4, pp. 321-331.
Chipp, K.F. and Chakravorty, D. (2016), "Producer push to consumer pull: who curates new media content? Developing strategies for new media environments", Fournal of Product $\mathcal{E}$ Brand Management, Vol. 25 No. 4, pp. 373-386.

Chua, A.Y. and Banerjee, S. (2015), "How businesses draw attention on Facebook through incentives, vividness and interactivity", IAENG International fournal of Computer Science, Vol. 42 No. 3, pp. 275-281.

Colliander, J., Dahlen, M. and Modig, E. (2015), “Twitter for two: investigating the effects of dialogue with consumers in social media", International fournal of Advertising, Vol. 34 No. 2, pp. 181-194.

Coyle, J.R. and Thorson, E. (2001), "The effects of progressive levels of interactivity and vividness in web marketing sites", fournal of Advertising, Vol. 30 No. 3, pp. 65-77.

Content Marketing Association (2016), "The CMA video engagement industry report", available at: http:// videoindustryreport.the-cma.com/ (accessed 16 July 2017).

Coxe, S., West, S.G. and Aiken, L.S. (2009), "The analysis of count data: a gentle introduction to Poisson regression and its alternatives", Fournal of Personality Assessment, Vol. 91 No. 2, pp. 121-136.

Creamer, M. (2012), "Study: only 1\% of Facebook 'fans' engage with brands - not many fans are creating content, but that might not be a bad thing", Advertising Age, available at: http://adage.com/article/digital/study-1-facebook-fans-engagebrands/232351/ (accessed 13 December 2017).

de Vries, L., Gensler, S. and Leeflang, P.S. (2012), "Popularity of brand posts on brand fan pages: an investigation of the effects of social media marketing", fournal of Interactive Marketing, Vol. 26 No. 2, pp. 83-91.

eMarketer (2015), "Increasing audience engagement key objective in social media marketing", October 26, available at: www.emarketer.com/Article/Increasing-Audience-EngagementKey-Objective-Social-Media-Marketing/1013148? ecid= NL1010 (accessed 2 November 2017).

Erskine, R. (2018), "Facebook engagement sharply drops 50\% over last 18 months", Forbes, August, available at: www. forbes.com/sites/ryanerskine/2018/08/13/study-facebookengagement-sharply-drops-50-over-last-18-months/\#68b c563c94e8 (accessed 2 September 2019).

Fisher, T. (2009), "ROI in social media: a look at the arguments", Fournal of Database Marketing \& Customer Strategy Management, Vol. 16 No. 3, pp. 189-195.

Fortin, D.R. and Dholakia, R.R. (2005), "Interactivity and vividness effects on social presence and involvement with a web-based advertisement", fournal of Business Research, Vol. 58 No. 3, pp. 387-396.

Fournier, S. and Avery, J. (2011), "The uninvited brand", Business Horizons, Vol. 54 No. 3, pp. 193-207.

Gavilanes, J.M., Flatten, T.C. and Brettel, M. (2018), "Content strategies for digital consumer engagement in social networks: why advertising is an antecedent of engagement", fournal of Advertising, Vol. 47 No. 1, pp. 4-23.

Halaszovich, T. and Nel, J. (2017), "Consumer-brand engagement and Facebook fan-page 'like'-intention", fournal of Product \& Brand Management, Vol. 26 No. 2, pp. 120-134.

Hilbe, J.M. (2014), "Modeling count data", Cambridge University Press: New York, NY. 
Hollebeek, L.D., Glynn, M.S. and Brodie, R.J. (2014), "Consumer brand engagement in social media: conceptualization, scale development and validation", Fournal of Interactive Marketing, Vol. 28 No. 2, pp. 149-165.

Kaplan, A.M. and Haenlein, M. (2010), "Users of the world, unite! The challenges and opportunities of social media", Business Horizons, Vol. 53 No. 1, pp. 59-68.

Kim, M. and Song, D. (2018), "When brand-related UGC induces effectiveness on social media: the role of content sponsorship and content type", International fournal of Advertising, Vol. 37 No. 1, pp. 105-124, available at: http:// doi. org/10.1080/02650487.2017.1349031

Lee, D., Hosanagar, K. and Nair, H. (2014), "The effect of social Media marketing content on consumer engagement: evidence from Facebook", Working Paper, Wharton School.

Lipsman, A., Mudd, G., Rich, M. and Bruich, S. (2012), "The power of 'like': how brands reach (and influence) fans through social-media marketing", Fournal of Advertising Research, Vol. 52 No. 1, pp. 40-52.

Liu, Y. (2003), "Developing a scale to measure the interactivity of websites", fournal of Advertising Research, Vol. 43 No. 2, pp. 207-216.

Liu, Y. and Shrum, L.J. (2002), "What is interactivity and is it always such a good thing? Implications of definition, person, and situation for the influence of interactivity on advertising effectiveness", fournal of Advertising, Vol. 31 No. 4, pp. 53-64.

Lohtia, R., Donthu, N. and Hershberger, E.K. (2003), "The impact of content and design elements on banner advertising click-through rates", fournal of Advertising Research, Vol. 43 No. 4, pp. 410-418.

Mangold, W.G. and Faulds, D.J. (2009), "Social media: the new hybrid element of the promotion mix", Business Horizons, Vol. 52 No. 4, pp. 357-365.

Petty, R.E. and Cacioppo, J.T. (1986), "The elaboration likelihood model of persuasion", Communication and Persuasion, Springer, New York, NY, pp. 1-24.

Pongpaew, W., Speece, M. and Tiangsoongnern, L. (2017), "Social presence and consumer brand engagement on Facebook brand pages", Fournal of Product \& Brand Management, Vol. 26 No. 3, pp. 262-281.

Porter, L. and Golan, G.J. (2006), "From subservient chickens to brawny men: a comparison of viral advertising to television advertising", fournal of Interactive Advertising, Vol. 6 No. 2, pp. 30-38.

PwC (2015), "Global entertainment and media outlook 20152019”, available at: www.pwc.com/gx/en/industries/ entertainment-media/outlook.html (accessed 1 December 2015).

Sabate, F., Berbegal-Mirabent, J., Cañabate, A. and Lebherz, P.H. (2014), "Factors influencing popularity of branded content in Facebook fan pages", European Management fournal, Vol. 32 No. 6, pp. 1001-1011.

Schulze, C., Schöler, L. and Skiera, B. (2014), "Not all fun and games: viral marketing for utilitarian products", fournal of Marketing, Vol. 78 No. 1, pp. 1-19.

Stephen, A.T., Sciandra, M. and Inman, J. (2015), "Is it what you say or how you say it? How content characteristics affect consumer engagement with brands on Facebook", Working Paper 19, Saïd Business School.
Steuer, J. (1992), "Defining virtual reality: dimensions determining telepresence", Fournal of Communication, Vol. 42 No. 4, pp. 73-93.

SocialBakers.com (2015), "Top five industries on Facebook (Ireland)", available at: www.socialbakers.com/resources/ reports/ireland/2015/january/ (accessed 13 September 2016).

Sundar, S.S. and Limperos, A.M. (2013), "Uses and Grats 2.0: new gratifications for new media", fournal of Broadcasting $\mathcal{E}$ Electronic Media, Vol. 57 No. 4, pp. 504-525.

Swani, K. and Milne, G.R. (2017), "Evaluating Facebook brand content popularity for service versus goods offerings", Fournal of Business Research, Vol. 79 (October), pp. 123-133.

Swani, K., Milne, G. and Brown, B.P. (2013), "Spreading the word through likes on Facebook: evaluating the message strategy effectiveness of fortune 500 companies", fournal of Research in Interactive Marketing, Vol. 7 No. 4, pp. 269-294.

Tafesse, W. (2016), “An experiential model of consumer engagement in social media", fournal of Product E Brand Management, Vol. 25 No. 5, pp. 424-434.

Taylor, D.G., Lewin, J.E. and Strutton, D. (2011), "Friends, fans, and followers: do ads work on social networks? How gender and age shape receptivity", fournal of Advertising Research, Vol. 51 No. 1, pp. 258-275.

Tellis, G.J., MacInnes, D.J., Tirunillai, S. and Zhang, Y. (2019), "What drives virality (sharing) of online digital content? The critical role of Brand information, emotion, and brand prominence", fournal of Marketing, Vol. 83 No. 4, pp. 1-20.

Trappey, R.J., III. and Woodside, A.G. (2005), "Consumer responses to interactive advertising campaigns coupling shortmessage-service direct marketing and TV commercials", fournal of Advertising Research, Vol. 45 No. 4, pp. 382-401.

Tsai, W.-H.S. and Men, L.R. (2013), "Motivations and antecedents of consumer engagement with brand pages on social networking sites", fournal of Interactive Advertising, Vol. 13 No. 2, pp. 76-87.

Van Doorn, J., Lemon, K.N., Mittal, V., Nass, S., Pick, D., Pirner, P. and Verhoef, P.C. (2010), "Consumer engagement behavior: theoretical foundations and research directions", Fournal of Service Research, Vol. 13 No. 3, pp. 253-266.

Vargo, C.J. (2016), "Toward a tweet typology: contributory consumer engagement with brand messages by content type", Fournal of Interactive Advertising, Vol. 16 No. 2, pp. 157-168.

Voorveld, H.A., van Noort, G., Muntinga, D.G. and Bronner, F. (2018), "Engagement with social media and social media advertising: the differentiating role of platform type", fournal of Advertising, Vol. 47 No. 1, pp. 38-54.

Warc (2016), "Social preferred for content discovery", available at: www.warc.com/Content/News/N36740_ Social_preferred_for_content_discovery.content?PUB $=$ Warc $\% 20$ News \&CID=N36740\&ID=c8a1441a-5bbd-486f-8de8$3351 \mathrm{~d} 24185 \mathrm{~b} 5 \& \mathrm{q}=$ social + preferred + for + conten $t+$ disco very\&qr= (accessed 13 May 2018).

Weiger, W.H., Hammerschmidt, M. and Wetzel, H.A. (2018), "Don't you dare push me: how persuasive social media tactics shape consumer engagement", Fournal of the Association for Consumer Research, Vol. 3 No. 3, pp. 364-378.

Zhang, J. and Mao, E. (2016), "From online motivations to ad clicks and to behavioral intentions: an empirical study of consumer response to social media advertising", Psychology E Marketing, Vol. 33 No. 3, pp. 155-164. 


\section{Further reading}

Dessart, L., Veloutsou, C. and Morgan-Thomas, A. (2015), "Consumer engagement in online brand communities: a social media perspective", Fournal of Product \& Brand Management, Vol. 24 No. 1, pp. 28-42.

Otondo, R.F., Van Scotter, J.R., Allen, D.G. and Palvia, P. (2008), "The complexity of richness: media, message, and communication outcomes", Information $\mathcal{E}$ Management, Vol. 45 No. 1, pp. 21-30.

Özbölük, T. and Dursun, Y. (2017), “Online brand communities as heterogeneous gatherings: a netnographic exploration of apple users", Fournal of Product $\mathcal{E}$ Brand Management, Vol. 26 No. 4, pp. 375-385.

Pentina, I., Guilloux, V. and Micu, A.C. (2018), "Exploring social media engagement behaviors in the context of luxury brands", fournal of Advertising, Vol. 47 No. 1, pp. 55-69.

\section{About the authors}

Dr Gillian Moran is an Assistant Professor in Marketing at the School of Business, Maynooth University, Maynooth, Ireland. Gillian's research interests lie in how brands use social media and digital marketing to connect and engage with consumers, as well as content marketing strategy design and eWOM. Her research has been published in the Journal of
Advertising Research and the fournal of Marketing Communications among others.

Dr Laurent Muzellec is an Associate Professor in Marketing at Trinity College Dublin, Dublin, Ireland. He is the Founder and Director of Trinity Centre for Digital Business. His research interests pertain to the field of branding strategies in interactive media and digital business model and the creation of value. His articles have appeared in several international publications, including Industrial Marketing Management, Marketing Theory, the Fournal of Product and Brand Management and the European fournal of Marketing. Laurent Muzellec is the corresponding author and can be contacted at: Laurent.muzellec@tcd.ie

Dr Devon Johnson is an Associate Professor of Marketing at Montclair State University, Montclair, New Jersey, USA. He has previously held academic appointments at Northeastern University, Boston, Massachusetts, USA, and at Emory University, Atlanta, Georgia, USA. Dr Johnson conducts research and consults with companies on marketing analytics and big data analytics implementation. His research has been published in the Fournal of Marketing Research, Fournal of the Academy of Marketing Science, Fournal of Business Research, Fournal of Interactive Marketing, Industrial Marketing Management, International Fournal of Bank Marketing and Fournal of Psychology \& Marketing, among others. 